\title{
A Study to Examine the Relationship between Social Support and Perception of Being Institutionalized among the Elderly Aged 65 Years and Above Who Are in Institutions in Bulawayo Urban, Zimbabwe
}

\author{
Sifisokuhle I. Dhlamini-Sibanda, Virgininia Dube-Mawerewere, Grace Nkhoma, \\ Clara 0. Haruzivishe \\ College of Health Sciences, University of Zimbabwe, Harare, Zimbabwe \\ Email:sdhlamini1972@gmail.com
}

How to cite this paper: Dhlamini-Sibanda, S.I., Dube-Mawerewere, V., Nkhoma, G. and Haruzivishe, C.O. (2017) A Study to Examine the Relationship between Social Support and Perception of Being Institutionalized among the Elderly Aged 65 Years and Above Who Are in Institutions in Bulawayo Urban, Zimbabwe. Open Journal of Nursing, 7, 905-917. https://doi.org/10.4236/ojn.2017.78067

Received: May 19, 2017

Accepted: August 15, 2017

Published: August 18, 2017

Copyright $\odot 2017$ by authors and Scientific Research Publishing Inc. This work is licensed under the Creative Commons Attribution International License (CC BY 4.0).

http://creativecommons.org/licenses/by/4.0/

(c) (i) Open Access

\begin{abstract}
Policies on the elderly in Zimbabwe are based on social networks and social capital in which the care of the elderly rests with the adult children and other relatives including the community. It is argued that social networks and social capital are informal and the weakness in these informal types of social support is that they are difficult to maintain in cases of urbanization, migration and socio-economic hardships. The study sought to examine the relationship between social support and the perception of being institutionalized among the elderly aged 65 years and above who were in institutions in Bulawayo urban. A descriptive quantitative cross-sectional correlational survey method was used. A simple random sampling method was used to recruit respondents. The sample size in this study was 81 respondents. Data was collected using the interview schedule. Analysis was done using the Statistical Package Social for Sciences (SPSS) package, descriptive and inferential statistics. The Pearson's correlation coefficient showed the relationship between social support and perception of being institutionalized as follows; $r=0.181, p=0.107$. This shows that there is no relationship between social support and perception of being institutionalized among the elderly aged 65 years and above who are in institutions in Bulawayo urban, Zimbabwe.
\end{abstract}

\section{Keywords}

Elderly, Social Support, Perception, Institutionalized 


\section{Background}

Aging is inevitable. The elderly's ability to carry out activities of daily living becomes difficult and deteriorates forcing them to be cared for in an institution. With the epidemiological transition, the rate of institutionalization of older adults has increased in various countries, and this process is occurring in Zimbabwe as well [1]. It is projected that with longevity more elderly people will be institutionalized.

Perception of being institutionalized is a socially constructed way of thinking about institutionalization. Positive perception of being institutionalized is when the elderly accept that ageing has physiological, psychological and social determinants such that institutionalization is necessary at some point in time [2]. Negative perception of being institutionalized is often based on negative attitudes and stereotypes that ageing is negative and being in an institution is worse. Institutionalization during old age therefore requires tremendous adaptability [3].

In a study conducted in India, 50\% of the respondents felt neglected by family, $32 \%$ had no contact with the outside world, and $68 \%$ felt that the attitude of people towards the elderly was that of neglect [4]. A related study further found that $48 \%$ of the institutionalised elderly felt sad because of poverty, this observation being made in Zimbabwe [5]. In Zimbabwe, the general perception is that the elderly in institutions are foreigners who are usually destitute with no one to care for them [6]. However, due to socio-economic and demographic changes more and more elderly people now accept that they can no longer depend on the adult children for support hence the need to be institutionalized [7]. Institutionalization is however, viewed as a borrowed culture and a dilemma for the black Zimbabwean hence adaptation is required to help the elderly live in institutions [6].

In some West African countries such as Kenya, the elderly especially the women flee from their rural homes to be destitute in cities for fear of being labelled as witches and being burnt alive, hence they are found in institutions. They view institutions as their only salvation, hence in that context, they tend to perceive institutionalization positively [7].

Due to socio-economic and demographic changes in Zimbabwe, more and more elderly people now accept that they can no longer depend on the adult children for support hence the need to be institutionalized [7]. It was predicted by research that there were indications that institutionalization of the elderly would become the answer to the problem of elderly care particularly in urban areas [8]. It is also important to note that policies on the elderly in Zimbabwe are based on social networks and social capital in which the care of the elderly rests with the adult children and other relatives including community [9] [10] [11]. It is argued that social networks and social capital are informal and the weakness in these informal types of social support is that they are difficult to maintain in cases of urbanization, migration and socio-economic hardships [7]. The under- 
lying assumption is that children will have resources to share and yet these poor children will have nothing to fall back on. The Madrid International Plan of Action on Ageing 2002, 2012 (MIPPA) argue that specifically in Africa, there is need for governments to honour and reciprocate "the investment made by older people to the well-being of the states" and thus to recognise "the debt which states owe these senior citizens" [12]. The government can do this by changing the social support policies.

A study on institutionalisation of the elderly revealed that relatives had differing perceptions of institutionalization, some being happy their elderly relatives were better cared for and others expressing guilty conscience over having their elderly relatives in an institution [6]. The elderly were happy about the care they were receiving from the institution but some were bitter about their relatives especially their children who put them in institutions [6]. When the elderly are placed into institutions, the assumption is that they will appreciate it and be happy but few studies have been done to ascertain their perception of being institutionalized and the effects it will have on their integrity. It is against this background that the researchers decided to examine the relationship between social support and perception of being institutionalized among elderly in institutions in Bulawayo urban as very few studies have been published on these two variables in this context.

\section{Objectives of the Study}

- To determine the level of social support of the elderly aged 65 years and above who are in institutions in Bulawayo urban.

- To determine the perception of being institutionalized among the elderly aged 65 years and above who are in institutions in Bulawayo urban.

- To examine the relationship between social support and the perception of being institutionalized among the elderly aged 65 years and above who are in institutions in Bulawayo urban

\section{Methods}

The researchers chose the descriptive quantitative cross-sectional correlational survey method as it gives a "snapshot" of the events at a particular moment in time [13]. It allows for determining the relationship between one variable and another [14]. In this particular study, the researcher wanted to determine the relationship between the social support and perception of being institutionalized among the elderly in institutions. The variable of perception of being institutionalised was conceptualised as the elderly's judgment on their acceptance of institutional life and care. This was operationalized through the Perception of being institutionalised Questionnaire. Social support was conceptualised as any information or feeling that led the elderly to believe that he/she was loved, cared for and had assistance from others and was an esteemed member of a mutual group or supportive network. This variable was operationalized using the Social 
Support Questionnaire.

This study was conducted in institutions in the urban area of Bulawayo in 2015. The institutions selected were Ekuphumuleni, Ingutsheni, Bartley Block and Edith Duly. A simple random sampling method was used to recruit respondents. The institutions were conveniently picked. The institutions were put into four strata. In the order of Bartley Block, Edith Duly's, Ekuphumuleni and Ingutsheni Hospital, a ratio of 1:1.25:1.75:2 was used to draw the respondents until a sample size of 84 was drawn. 14 respondents were drawn from Bartley Block, 17 from Edith Duly's, 24 from Ekuphumuleni and 29 from Ingutsheni Hospital. From each institution simple random sampling was used to recruit the respondents. The study included elderly persons who were 65 years and over who were in an institution. The respondents were able to communicate in isiNdebele or English. The study excluded elderly who did not communicate in isiNdebele or English.

To calculate the sample size, the formula $\mathrm{n}=[\mathrm{Z} \delta / \Delta]^{2}$ was used. The significance level was set at 0.05 , where $z$ is the confidence level, $\delta$ is the variance, $\Delta$ is the effect size [15]. A sample size of 84 respondents was recruited into the study to allow for attrition. One respondent refused to participate and the other two had incomplete data resulting in a sample size of 81 .

$$
\begin{gathered}
\mathrm{Z}=1.96, \delta=21, \Delta=5 \\
(1.96 \times 21 / 5)^{2}=67.7
\end{gathered}
$$

Power of 0.80

$$
67.7 / 0.80=84
$$

The study used the stratified random sampling method. Stratified random sampling is a variant of simple random sampling in which the population is divided into two or more strata [16]. A sampling frame was drawn for all the clients that met the inclusion criterion. Using the ratio of 1:1.25:1.75:2, simple random sampling was used to recruit the sample of 84 respondents.

\section{Data Collection Procedure}

Preliminary permission was sought from the Joint Research Ethics Committee of Parirenyatwa Group of Hospitals and College of Health Sciences (JREC) through the Nursing department, then from the respective Chief Executive Officers (CEO) and the matrons of the respective institutions. The final permission was granted by the Medical Research Council of Zimbabwe. The unit matrons and the sisters-in-charge were informed to gain co-operation and arrange interview dates and times. When permission had been granted, individual respondents had the study explained to them including risks and benefits so that they could consent to participate. Interviews were conducted in a place where other clients and staff of the institution did not disturb and no one was allowed to be present during interviews. Data was analysed using the Statistical Package Social for Sciences (SPSS) package, descriptive and inferential statistics. 


\section{Results and Discussion}

\subsection{Sample Demographics}

The sample was composed of eighty-one respondents who were selected randomly after the stratification of the institutions. The modal age was eighty-one. The age ranges with least frequencies were 71 - 75 with twelve (14.8\%) and 76 80 with ten (12.3\%). The steep downward slope can be explained by the AIDS/ HIV pandemic that was claiming a lot of lives before the introduction of antiretroviral drugs. At the time HIV prevalence was around 33\%. This was followed by a steep upward slope of the $65-70$ range with twenty-two (27.2\%), the range with the highest frequencies. Literature revealed that the elderly population is fast growing due to improved health care and living standards the world over [1] [10] [11].

There were fifty-three (65.4\%) males and twenty-eight (34.6\%) females in the sample, indicating that there are more males in the institutions than females. Culturally, the care of the elderly lies with the daughters-in-law because it is perceived to be easier to care for the elderly female than males at home [7] [17]. Also due to emigration of the younger population groups in search of greener pastures and also due to AIDS related deaths, more elderly females are taking care of their grandchildren at home. In the light of that predicament, male gender has consistently been identified as predisposing factor to institutionalization concurring with the study findings [18].

Earlier research has identified marital status as a predictor of using institutional care among the elderly [19]. The findings of the study concur with existing literature that older adults with spouses are $90 \%$ less likely to be institutionalized. Only six (7.4\%) were married. The majority of the respondents were widowed, thirty (37\%), followed by the divorced, twenty-six (32.1\%) and then the single, nineteen (23.5\%). As stated that elderly people tend to experience several losses of close relatives including spouse leaving them with no-one to care for them, this could be the major reason for institutionalization [11].

Forty $(49.4 \%)$ respondents were sent to the institutions by their relatives, while twelve (14.8\%) went to the institution on their own, twelve $(14.8 \%)$ were sent by the social worker. Seventeen $(21 \%)$ were sent by others who included neighbours, police, former employers and church mates. The general perception of institutionalization was that institutions were for foreigners who had no-one to look after them [6]. The above finding disputes this as the elderly are volunteering to be institutionalized and the relatives and community are turning to institutions for elderly care as observed by earlier researchers that institutionalization will be the solution to adult care in the near future [8]. It would seem that the predicted future for the predicament of the elderly has come. The fact that social services attended to the least number of respondents concurs with the assertion that policies on elderly in Zimbabwe are based on social networks and social capital in which the care of the elderly rests with the adult children and other relatives including community [7] [9]. 
The same number of respondents, thirty-five (43.2\%) were institutionalized because they were either not feeling well or had no-one to care for them. Eleven (13.6\%) did not know why they were institutionalized. These are the people who could have been institutionalized against their will and no-one bothered to explain to them why they are institutionalized, making them very bitter resulting in a negative perception towards institutionalization [1]. As a result adaptation to institutional life could fail predisposing them to worsening of age-related illnesses.

\subsection{Perception of Being Institutionalized}

Seven items were used to assess perception of being institutionalized. Responding to whether the elderly enjoyed staying at the institution, twenty-five (30.9\%), constituting the majority, strongly disagreed showing negative perception of being institutionalized. It has been observed that institutionalization is a borrowed culture and dilemma for black Zimbabweans, some are still resistant to institutionalization [7]. The other reasons for not enjoying staying at the institution could be what is described as "architectural paternalism and policy and legal framework regulated care" [20]. "Architectural paternalism" is described as a phenomenon in which high buildings, the fence and locks are used to isolate the clients from the whole society and keep family members and friends away which is viewed as severing social networks and preventing social support. Policy and legal framework regulated care is described as a situation in which policies are used to limit clients' autonomy such as locking the door to prevent clients from absconding or wandering off, not leaving the institution without relative to escort and routines for activities of living. These make the elderly feel devalued and treated as non-persons thereby increasing feelings of dependency and despair [21].

Fourteen (17.3\%) somewhat disagreed and twenty $(24.7 \%)$ somewhat agreed that they enjoyed being in an institution. This shows that the elderly are indifferent about institutionalization. Since institutionalization seems fairly new among black Zimbabweans, it has been pointed out that the elderly may be in the transition period, needing intervention so that adaptation can occur [6]. Twenty-two (27.2\%) strongly agreed showing positive perception of being institutionalized. These particular respondents could have realised that they can no longer depend on their children for care. These are well adapted individuals who are not anxious about institutionalization and are likely to age successfully [6].

With increasing health care requirements and failing family care the majority; twenty-eight (34.6\%) elderly reported being less sick post institutionalization. Previous studies found that there were improvements in health after moving into institutions [19].

The study further showed that $(59.3 \%)$ of respondents strongly disagreed that they could contribute to the community. Previous studies have indicated that the elderly in institutions lose their self-worth and feel that they have nothing to contribute to the community [2]. They fail to recognise that as custodians of 
culture and customs they have a responsibility to pass culture to the younger generation [6]. In the study context, this could indicate role loss which is a negative perception.

There is a small difference between those who strongly agreed (twenty-six; $32.1 \%$ ) and those who strongly disagreed (twenty-five; 30.9\%) that they have control over their lives despite institutionalization. Empirical evidence has observed that lack of autonomy was common among elderly resident in institutions [21]. Factors leading to loss of autonomy include loss of independence, lack of flexibility in granting residents' requests, not being consulted to contribute on decisions affecting their care and policy and legal regulated care approach [20] [21]. However some literature noted that some old people felt respected, secure and safe in the institutions and as long as necessities were provided [2] [21]. The respondents' neutrality in the study context could have been influenced by the recency of the phenomenon of elderly institutionalisation, so they were not sure whether their predicament translated to having control over their lives or not.

Studies done in developed countries such as America show that institutionalization is an alternative to home care [22]. Thirty-six (44.4\%) strongly agreed that institutionalization is an alternative to home care. These individuals were those who seemed to have adapted to institutionalization and had a positive perception. However twenty-five (30.9\%) strongly disagreed. These individuals perceived institutionalization as total rejection and could be bitter towards their family members for putting them in institutions [6] [18]. The remaining twenty (24.7\%) were indifferent. They were resigned to their fate.

Forty (49.4\%) strongly accepted institutionalization as a way of looking after the elderly when the family is no longer able to care of them. As noted in earlier studies in Zimbabwe that the elderly are becoming aware that they can no longer rely on family members for care and support due to socio-economic and cultural dynamics, more are turning to institutions for care [6] [7]. In China, it was noted that there is change in perception of institutionalization with more elderly people perceiving institutionalization positively [19]. Twenty (24.7\%) strongly disagreed. These individuals believe that it was imperative for family members to take care of their elderly.

Human beings are naturally commune and being among other people reduces feelings of loneliness and rejection. Thirty-eight (46.9\%) respondents strongly agreed that it is better to be in an institution than being at home alone. As observed from earlier studies that the elderly preferred to be in an institution where they get better care and have other people to talk to. The elderly have also been reported to have observed that their children/significant others are too busy to talk to them resulting in them spending more time on their own culminating in feelings of isolation [22]. Twenty-three (28.4\%) strongly disagreed preferring to be home alone. These individuals had negative perception of being institutionalized. Being in an institution made them feel unwanted and dumped. 
Results from this study show that the majority (thirty-two; 38.3\%) of the elderly in institutions had an indifferent perception of being institutionalized. Twenty-eight (34.6\%) had a positive perception while twenty-one (27.2\%) had a negative perception of being institutionalized. This can be explained by a number of factors. Indifference may be explained by prevailing poverty in institutions, especially public institutions [5]. At the time of the study, the country was trying to recover from an economic crisis of 2008-2009 which plunged it into poverty including institutions. Institutions experienced little to no government support and dwindling donor support [5]. The elderly found themselves being caught in between home and institution. They left their homes because their families were no longer able to care for them, now the institutions failed to provide the necessities putting them in a dilemma of not knowing which place is better than the other.

The second factor may be that the country was in a transition period at the time of the study. The general perception used to be that institutions are for foreigners and destitute, but now people are coming to institutions seeking admission [6]. Adaptation is a process. It will take time before everyone accepts institutionalization as an alternative to home care and solution to caring for the aging population. The third factor may be culture. These are elderly people who cannot just throw away their culture and adopt a new one. They may see the benefit but have reservations about it. The forth factor could be what is described as a syndrome specific to institutionalized elderly which is yet to be defined which is characterized by apathy and indifference [23]. For those with positive perception of being institutionalized, they seemed to appreciate the benefits of being institutionalized.

\subsection{Social Support}

Ten items were used to measure social support of the elderly in institutions. Social support is complex. It is personal and can only be defined by the beholder. Several studies argue that sources of emotional support, in order of importance, are spouse/partner, children, other relatives, friends, neighbours and formal organizations [10] [11] [17] [24] [25]. However from this study, fifty-one (63\%) stated that they did not get any help from their relatives when they need it. In the study relatives included spouse/partner, children and other relatives.

Asked whether there was someone who offered the elderly help when they needed it, twenty-nine (35.8\%) who constituted the majority strongly disagreed. This is connected to the fact that the majority had lost contact with their relatives. They, however, failed to recognise the institution, nurses and other residents as a social support system. Instrumental support is more evident and appreciated when it is coming from significant others [17].

Responding to the questions on whether the elderly had people with whom they felt at ease to talk to about what was on their minds, twenty-four (29.6\%) strongly agreed, while the majority, twenty-nine $(35.8 \%)$ somewhat agreed. If 
they had no communication with relatives, friendships might have developed within and among the residents and had become so strong they could confide in one another in a satisfactory manner.

Twenty-six (32.1\%) being the majority of the respondents strongly agreed that there was someone who appreciated them as a person and made them happy. Responding to the question on whether there was someone who made the elderly feel loved and honoured, the majority, twenty-seven (33.3\%) strongly agreed. From the above results, it is clear that the elderly had established social support systems within the institutions and these systems were serving a purpose. Such elderly people were less likely to feel lonely.

The majority of the respondents (49.4\%) strongly agreed that they got help from nursing staff when they needed it always. The majority (35.8\%) also strongly agreed that they had enough information they needed to undertake activities of living so that they could live with limited dependency on nursing staff and other clients. As ageing progresses, dementia may set in and the elderly constantly needs to be reoriented to reality and be updated on daily activities and may need to be reminded about engaging in activities of living [11]. In the institutions, it is the responsibility of the nursing staff. Nurses with adequate information on ageing process can be a valuable source of social support as they are able to respond appropriately thus creating trusting relationships with the elderly [23].

However the fact that respondents get help when they need it from the nursing staff but fail to appreciate the support aspect may be due to limited time and staff shortages where procedures are done in a hurry and clients only realise them as duty being done [21]. Due to lack of gerontologically prepared nursing staff, the nursing staff may not be aware that they are a form of social support to the client, therefore they may not respond to social needs of the client but only to the nursing activities they are employed to do. It is also possible that respondents may fail to recognize the supportive aspect of the nursing staff due to negative attitudes of some nursing staff [5].

Twenty-four (29.6\%) respondents somewhat agreed and twenty-three (28.4\%) strongly disagreed that there was someone who gave the elderly information they needed and kept them updated so that they did not feel out of touch with what was happening around them. This shows that clients lack informational social support. This confirms earlier findings from research that when an elderly is admitted to an institution they lose touch with family and outside world and social networks are interrupted [1]. This also confirms the earlier findings that due to staff shortages, nursing staff have no time to discuss social issues with clients [21].

To check if the elderly realised situations where they needed to ask for support (support seeking behaviours), two items were used. According to available literature, support seeking behaviour is especially important during appraisal of stress if one assesses if the demand exceeds his/her personal resources [23] [24]. 
Forty-four (54.3\%) of respondents strongly agreed that they asked for help when they needed it always. Forty-four (54.3\%) respondents strongly agreed that in critical times, they asked for other people's advice. From the results, the level of the social support of the elderly in institutions is moderate as evidenced by fortyone $(50.6 \%)$ respondents.

\subsection{Relationship between Social Support and Perception of Being Institutionalised}

The Pearson's correlation coefficient showed the relationship between social support and perception of being institutionalized as follows $r=0.181, p=0.107$, $\mathrm{p}<0.05$. This shows that there is no relationship between social support and perception of being institutionalized among the elderly aged 65 years and above who are in institutions in Bulawayo urban. Form the study, the age was negatively correlated with the perception of being institutionalized $(r=-0.247, p=$ $0.026)$, the elderly's ability to contribute to the community $(r=-251, p=0.024)$, the elderly's feeling of being in control of their lives despite being institutionalized $(r=-0.222, p=0.047)$ and whether the elderly accept institutionalization as an alternative to home care $(r=-0.382, p=0.000)$.

From the results, there is no relationship between social support and perception of being institutionalized among the elderly in institutions in Bulawayo. This disputes the earlier findings that the elderly in institutions in Zimbabwe are bitter and have negative perception about institutionalization and that they have poor social support [5]. Only five (6.2\%) reported poor social support. This then means that adaptation to institutional life has very little or nothing to do with social support.

However there are important findings regarding age. Form the study, the age was negatively correlated with the elderly's perception of being able to contribute something to the community $\left(r=-0.251^{\star}\right)$. This shows role loss and low self-esteem. Admittedly, they may not be able to contribute physically or financially but they are the custodians of a culture that needs to be passed on. That, they can contribute. On the other hand, they have no-one to teach in the institutions but instead, they themselves are the ones being taught by younger people (staff caring for them). So the institutions have usurped that role from them. This can explain the bitterness and resentment towards role loss as observed in a related study among the elderly in Masvingo [6] [7]. Some intervention to change this perception is essential.

Age was also negatively correlated with the elderly's feeling of being in control of their lives since being institutionalized $\left(r=-0.222^{\star}\right)$. This shows that as age increases, people tend to give up on life and just wait to die. This is described as fatalism [2]. In Zimbabwe, there is a culture of restricting things and activities that elderly can engage in. As a person ages they feel obliged to conform to this "behave as an adult" doctrine and in the process they lose the ability to control their own destiny. 
Age was also negatively correlated with the elderly's acceptance of institutionalization as an alternative to home care $\left(r=-0.382^{\star}\right)$. This may be influenced by deterioration in the ability to independently carry out activities of living where the elderly would prefer to depend on family members rather than nursing staff with whom they have an impersonal relationship. The elderly prefer to be at home with their families [1].

Age was also negatively correlated with perception of being institutionalized $\left(r=-0.247^{\star}\right)$. This means that as the age increases perception of being institutionalized becomes more negative. As noted in literature that negative perception of being institutionalized is associated with several negative physical and mental outcomes, its combination with advanced age can be deleterious for the elderly [18] [26]. Negative perception of being institutionalized among the elderly is the major contributing factor to morbidity and mortality among institutionalized elderly [27]. This means that the elderly in Zimbabwe are at risk.

\subsection{Implications to Psychiatric and Mental Health Nursing}

Results from this study showed that thirty-two (38.3\%) respondents were indifferent about being institutionalized, twenty-one (27.2\%) had negative perception of being institutionalized. This shows poor mental health. A mentally healthy individual should be able to adjust and adapt to any situation, including institutionalization. The elderly with negative perception are at risk of worsening age-related illnesses resulting in unsuccessful aging leading to fast deterioration in mental and physical health and death.

With more people living to old age, if not adequately prepared for institutionalization, there may be an increase in age-related mental problems affecting the elderly. The fact that more elderly will be institutionalized, there is going to be an impact on the quality of care of the elderly in the institutions which can either be positive or negative. Quality of care may improve if more nursing homes are opened and compete for clients. If the existing institutions remain the only ones available, quality of care is likely to deteriorate due to decreasing returns to scale.

There is need for psychiatric nurses to advocate for programs that focus on improving the perception of being institutionalized as noted by its negative correlation with age.

\section{Limitations of the Study}

There were few limitations encountered during the carrying out of the study.

1) The results of the study cannot be generalized beyond Bulawayo because the study was done on a small sample.

2) The instrument was designed by the investigator and has never been subjected to validity testing.

\section{References}

[1] Vitorino, L.M., Paskulin, L.M.G. and Vianna, L.A.C. (2013) Quality of Life of Se- 
niors Living in the Community and in Long Term Care Facilities: A Comparative Study. Original Article, 21, 3-11. https://doi.org/10.1590/S0104-11692013000700002

[2] Singh, S., Raut, N.B., Subramanyan, A.A., Kamath, R., Pinto, C. and Shanker, S. (2014) Perception of Old Age and Self: A Comparative Study of Elderly Females Living in Community and in Old Age. Journal of Geriatric Mental Health, 1, 32-37. https://doi.org/10.4103/2348-9995.141923

[3] Melendez-Moral, J.C., Charco-Ruiz, L., Maryodomo-Rudriguez, T. and Sales-Galan, A. (2013) Effects of a Reminiscence Program among Institutionalised Elderly Adults. Psicothema, 25, 319-323.

[4] Lena A., Ashok, K., Padma, M., Kamath, V. and Kamath. A. (2009) Health and Social Problems of the Elderly: A Cross-Sectional Study in UdupiTaluk, Karnataka. Indian Journal of Community Medicine, 34, 131-134. https://doi.org/10.4103/0970-0218.51236

[5] Hungwe, C. (2010) Evaluating Older Persons' Perception on Their Quality of Life in an Old People's Institution: A Zimbabwean Case Study. Journal of Applied Gerontology, 29, 333-351. https://doi.org/10.1177/0733464809339626

[6] Chindedza, W., Mupfumira, I.M. and Madungwe, L.S. (2013) Old People's Homes: A Borrowed Culture; A Dilemma for the Black Zimbabwean. A Case Study of Mucheke Old People's Home. Great Zimbabwe University, Masvingo.

[7] Gwadamirai, N. (2009) A Study on the Role of Old Age Instututions in the Care of the Elderly People in the Context of Hyperinflation: A Case of Mucheke, Masvingo, Zimbabwe. University of Kwa-Zulu Natal, Kwa-Zulu Natal.

[8] Kaseke, E. (1991) Social Work Practice in Zimbabwe. Journal of Social Development, 6, 33-45.

[9] World Bank Group (2009) Social Capital. Available Online at http://go.worldbank.org/C0QTRW4QF0

[10] Dhemba, J. (2013) Social Protection for the Elderly in Zimbabwe: Issues, Challenges and Prospects. African Journal of Social Work, 3, 1-22.

[11] Dhemba, J. and Dhemba, B. (2015) Aging and Care of Older Persons in Southern Africa: Lesotho and Zimbabwe Compared. Social Work and Society International Online Journal, 13, 1-16.

[12] Aboderin, I. (2005) Understanding and Responding to Aging, Health, Poverty and Social Change in Sub-Saharan Africa: A Strategic Framework for Research. University of Oxford, Oxford.

[13] Grove, S.K., Burns, N. and Gray, J. (2012) The Practice of Nursing Research. Appraisal, Synthesis and Generation of Evidence. Elsevier, Saunders.

[14] Labaree, R.V. (2013) Organising your Social Sciences Paper. University of California, California.

[15] Lenth, R.V. (2001) Some Practical Guidelines for Effective Sample-Size Determination. University of Iowa, Iowa.

[16] Polit, D.F. and Beck, C.T. (2012) Nursing Research. Generating and Assessing Evidence for Practice. Williams \& Wilkins/Wolters Kluwer, Philadelphia.

[17] Chalise, H.N., Kai, I. and Saito, T. (2010) Social Support and Its Correlation with Loneliness: A Cross Cultural Study of Nepalise Adults. International Journal of Aging and Human Development, 71, 115-138. https://doi.org/10.2190/AG.71.2.b

[18] Luppa, M., Sikorski, C., Luck, T., Ehreke, L., Konnopka, A., Wiese, B., Weyerer, S., Konig, H.H. and Reidel-Heller, S.G. (2012) Age- and Gender-Specific Prevalence of 
Depression in Latest-Life-Systematic Review And Meta-Analysis. Journal of Affective Disorders, 136, 212-221. https://doi.org/10.1016/j.jad.2010.11.033

[19] Chen, H.L. (2012) Everyday Experience of Frontline Professionals and In/Formal Carers: Long Term Care of Older People in England, the Netherlands and Taiwan. International Journal of Public and Private Health Care Management and Economics, 2, 21-40. https://doi.org/10.4018/ijpphme.2012070103

[20] Chow, W.S. and Priebe, S. (2013) Understanding Psychiatric Institutionalisation: A Conceptual Review. BMC Psychiatry, 13, 169. https://doi.org/10.1186/1471-244X-13-169

[21] Kimondo, J.W. (2012) Benefits and Challenges Encountered by Elderly Living in Nursing Homes. ARCADA, Kenya.

[22] Rodriguez-Martin, B., Martinez-Andres, M., Cervera-Monteagudo, B., NotarioPacheco, B. and Martinez-Vizcaino, V. (2013) Perception of Quality of Care among Residents of Public Nursing Homes in Spain: A Grounded Theory Study. BMC Geriatrics, 13, 65. https://doi.org/10.1186/1471-2318-13-65

[23] Cobo, C.M.S., Perez, V., Hermosilla, C., Nunez, M.J. and de Lorena, P. (2014) Prevalence of Sarcopenia in Elderly with Dementia Institutionalised: A Multicentre Study. The Journal of Aging Research and Clinical Practice, 4, 228-235.

[24] Melchiorre, M.G., Chiatti, C., Lamura, G., Torres-Gonzales, F., Stankunas, M., Lindert, J., Loannidi-Kapolou, E., Barros, H., Macassa, G. and Soares, J.M. (2013) Social Support, Socio-Economic Status, Health and Abuse among Older People in Seven European Countries. PLoS ONE, 8, E54856.

https://doi.org/10.1371/journal.pone.0054856

[25] Duci, V. and Tahsini, I. (2012) Perceived Social Support and Coping Styles as Moderators for Level of Anxiety, Depression and Quality of Life in Cancer Care Givers: A Literature Review. European Scientific Journal, 8, 160-175.

[26] Cherry, K.E., Marks, L.D., Benedetto, T., Sullivan, M.C. and Barker, A. (2013) Perceptions of Longevity and Successful Aging in Very Old Adults. Journal of Religious Spiritual Aging, 25, 10. https://doi.org/10.1080/15528030.2013.765368

[27] Nemade, R., Reiss, N.S. and Dombeck, M. (2007) Depression: Major Depression and Unipolar Varieties. https://www.mentalhelp.net/

\section{Submit or recommend next manuscript to SCIRP and we will provide best} service for you:

Accepting pre-submission inquiries through Email, Facebook, LinkedIn, Twitter, etc. A wide selection of journals (inclusive of 9 subjects, more than 200 journals)

Providing 24-hour high-quality service

User-friendly online submission system

Fair and swift peer-review system

Efficient typesetting and proofreading procedure

Display of the result of downloads and visits, as well as the number of cited articles

Maximum dissemination of your research work

Submit your manuscript at: http://papersubmission.scirp.org/

Or contact ojn@scirp.org 